\title{
The Questionnaire for Urinary Incontinence Diagnosis (QUID): Validity and Responsiveness to Change in Women Undergoing Non-Surgical Therapies for Treatment of Stress Predominant Urinary Incontinence
}

\author{
Catherine S. Bradley, MD, MSCE${ }^{1}$, David D. Rahn, MD², Ingrid E. Nygaard, MD, MS ${ }^{3}$, \\ Matthew D. Barber, MD, MHS ${ }^{4}$, Charles W. Nager, MD ${ }^{5}$, Kimberly S. Kenton, MD ${ }^{6}$, Nazema \\ Y. Siddiqui, MD ${ }^{7}$, Robert B. Abel, PhD $^{8}$, Cathie Spino, DSc $^{8}$, Holly E. Richter, PhD, MD $^{9}$, and \\ Pelvic Floor Disorders Network \\ ${ }^{1}$ Department of Obstetrics and Gynecology, University of lowa Carver College of Medicine, lowa \\ City, lowa \\ ${ }^{2}$ Department of Obstetrics \& Gynecology, University of Texas Southwestern Medical Center, \\ Dallas, Texas \\ ${ }^{3}$ Department of Obstetrics and Gynecology, University of Utah, Salt Lake City, Utah \\ ${ }^{4}$ Obstetrics, Gynecology, and Women's Health Institute, Cleveland Clinic, Cleveland Ohio \\ 5Department of Obstetrics and Gynecology, University of California San Diego, San Diego, \\ California \\ ${ }^{6}$ Departments of Obstetrics \& Gynecology and Urology, Loyola University Medical Center, \\ Maywood, Illinois \\ ${ }^{7}$ Department of Obstetrics and Gynecology, Duke University School of Medicine, Durham, North \\ Carolina \\ ${ }^{8}$ Department of Biostatistics, University of Michigan, Ann Arbor, Michigan \\ ${ }^{9}$ Department of Obstetrics and Gynecology, University of Alabama at Birmingham, Birmingham, \\ Alabama
}

\section{Abstract}

\begin{abstract}
Aims-The Questionnaire for Urinary Incontinence Diagnosis (QUID), a 6-item urinary incontinence (UI) symptom questionnaire, was developed and validated to distinguish stress and urge UI. This study's objective was to evaluate QUID validity and responsiveness when used as a clinical trial outcome measure.
\end{abstract}

\begin{abstract}
Methods-Participants enrolled in a multi-center trial of non-surgical therapy (continence pessary, pelvic floor muscle training or combined) for stress-predominant UI completed baseline and 3-month diaries, the Urinary Distress Inventory (UDI) and QUID. Data from all treatment groups were pooled. QUID internal consistency (Cronbach's $\alpha$ ) and convergent/discriminant
\end{abstract}

\footnotetext{
Corresponding Author: Catherine S. Bradley, MD, MSCE, University of Iowa Hospitals \& Clinics, Department of Obstetrics \& Gynecology, 200 Hawkins Drive, Iowa City, IA 52242, Business phone: (319) 356-1534, Fax: (319) 384-8620, catherinebradley@uiowa.edu.

Linda Brubaker led the review process.

Presented at the Annual Meeting of the American Urological Association, Chicago, Illinois, April 25-30, 2009.
} 
validity (Pearson correlations) were evaluated. Responsiveness to change was assessed with 3month score outcomes and distribution-based measurements.

Results-444 women (mean age 50) were enrolled with stress ( $=200)$ and mixed (N=244) UI; 344 had 3-month data. Baseline QUID Stress and Urge scores (both scaled 0-15, larger values indicating worse UI) were $8.4 \pm 3.2$ and $4.5 \pm 3.3$, respectively. Internal consistency of QUID Total, Stress and Urge scores was $0.75,0.64$ and 0.87 , respectively. QUID Stress scores correlated moderately with UDI-Stress scores $(\mathrm{r}=0.68, \mathrm{p}<0.0001)$ and diary stress UI episodes $(\mathrm{r}=0.41$, $\mathrm{p}<0.0001)$. QUID Urge scores correlated moderately with UDI-Irritative scores $(\mathrm{r}=0.68$, $\mathrm{p}<0.0001)$ and diary urge UI episodes $(\mathrm{r}=0.45, \mathrm{p}<0.0001)$. 3-month QUID Stress and Urge scores improved (4.1 \pm 3.4 and $2.2 \pm 2.7$, both p<0.0001). QUID Stress score Effect Size (1.3) and Standardized Response Mean (1.2) suggested a large change after therapy.

Conclusion-The QUID has acceptable psychometric characteristics and may be used as a UI outcome measure in clinical trials.

\section{Keywords}

Questionnaires; Urinary Incontinence, Stress; Reliability and Validity; Outcome Assessment

\section{Introduction}

Urinary incontinence (UI) occurs in approximately $16 \%$ of adult women (1). The most common types of UI are stress urinary incontinence (SUI), urge urinary incontinence (UUI) or a combination of both (mixed UI). SUI is commonly treated with pelvic floor exercises, pessaries, or surgery, while UUI is commonly treated with behavior modification and/or drug therapy, so it is important to accurately diagnose UI type. Incontinence type is often diagnosed by history, with confirmation by office evaluation or urodynamic testing; however, history is often the most important contributor to diagnosis (2). For this reason, UI symptom questionnaires are valuable research and patient care instruments.

The Questionnaire for Urinary Incontinence Diagnosis (QUID) is a self-administered, 6-item questionnaire designed to distinguish between SUI and UUI (3). It was developed through a rigorous process using literature review, review by clinical and methodological experts and screening in patients. The QUID is reliable and valid in diagnosing the type of incontinence, when compared to standard clinical evaluation in an outpatient urogynecology setting (3).

Validation of a research instrument is ongoing process, and the psychometric properties of any tool may differ in populations with different disease prevalence and characteristics. While the QUID has been shown to be a valid and reliable diagnostic tool for UI type, its value as an outcome measure for treatment studies of UI has not been evaluated. The Ambulatory Treatments for Leakage Associated with Stress Incontinence (ATLAS) trial is a multi-center randomized trial of non-surgical therapy for stress or stress-predominant mixed UI (4). This study is well-suited to further evaluate the QUID's psychometric characteristics. Our objective was to assess the construct validity and responsiveness to change of the QUID in women with stress and stress-predominant mixed incontinence who undergo non-surgical therapy.

\section{Materials and Methods \\ Study Design and Participants}

This was a prospectively-planned ancillary analysis of the ATLAS trial performed by the Pelvic Floor Disorders Network (PFDN). All PFDN sites obtained local institutional review board approval and all participants completed informed consent. Adult women with SUI and 
mixed (stress predominant) UI were enrolled and randomized to treatment with a continence pessary, behavioral therapy including pelvic floor muscle training or combined therapy (continence pessary plus behavioral therapy) (4). Eligibility criteria included at least 2 SUI episodes on a 7-day bladder diary and more SUI episodes than other types of UI episodes recorded on the diary. Women with continuous urinary leakage, current UI drug therapy, stages III or IV pelvic organ prolapse (5), incomplete bladder emptying or neurologic disorders associated with UI were excluded.

\section{Outcome Measures}

Demographics, medical history and physical examination including Pelvic Organ Prolapse Quantification (POP-Q) (5) were completed on enrollment. At baseline and 3 months after randomization, ATLAS participants completed self-administered validated questionnaires including the QUID and a 7-day bladder diary, on which they recorded numbers of voids and UI leakage episodes by incontinence type (stress, urge or other). Participants were grouped by the presence or absence of UUI episodes on the baseline bladder diary into mixed UI ( $\geq 1$ UUI episode recorded) and stress UI (no UUI episodes recorded) groups.

The QUID (Appendix) identifies the presence and frequency of stress and urge UI symptoms (3). Three items focus on stress incontinence symptoms and three on urge incontinence symptoms. Each item includes 6 frequency-based response options, ranging from "none of the time" to "all of the time", which are scored from 0 to 5 points. Scores are calculated in an additive fashion, resulting in separate Stress and Urge scores, each ranging from 0 to 15 points. Compared to a formal clinical evaluation performed in urogynecology patients, use of QUID scores (Stress scores $\geq 4$ for SUI and Urge scores $\geq 6$ for UUI) identified UI type accurately in $80 \%$ of participants (3).

Urinary incontinence-specific quality of life (QOL) instruments included the Urinary Distress Inventory (UDI) and Urinary Impact Questionnaire (UIQ) (6). Higher UDI and UIQ scale scores reflect increasing symptom bother and greater impact on daily activities from UI symptoms, respectively. Urinary incontinence severity was assessed using the Incontinence Severity Index (ISI), a validated 2-item questionnaire focusing on UI frequency and volume. Responses to each item are multiplied to obtain a severity score, which may be categorized as slight, moderate, severe and very severe (7).

In addition to UI-specific questionnaires, sexual function was characterized using the Pelvic Organ Prolapse-Urinary Incontinence Sexual Function Questionnaire (PISQ-12) (8) and the Short Form Personal Experience Questionnaire (SPEQ) (9). Higher scores for both reflect better sexual function. The Medical Outcomes Study Short Form (SF-36) Mental Component Summary (MCS) and Physical Component Summary (PCS) scores (10) and the Health Utility Index (HUI) (11) were completed to assess overall health-related QOL (SF-36) and health status (HUI). Higher scores for each indicate better function.

Three months after randomization, participants also completed the Patient Global Impression of Improvement (PGI-I) (12). This single item asks the participant to rate improvement of her continence status using a 7 -point response scale (1-very much better, 2much better, 3-a little bit better, 4-no change, 5-a little bit worse, 6-much worse and 7-very much worse).

\section{Statistical Analysis}

Continuous variables were summarized by the mean, standard deviation (SD), median, interquartile range (IQR) and range. Categorical variables were summarized by counts and percentages. At baseline, group characteristics and scores were compared using the Fisher's exact test or chi-square test (for categorical outcomes), the Wald test from an ordinal logistic 
regression model (for ordinal outcomes) or the two-sample Wilcoxon test (for continuous outcomes).

Convergent and discriminant validity were assessed by calculating correlations (Pearson or Spearman) between baseline QUID Total, Stress and Urge scores and various diary and questionnaire-based UI outcomes and other health-related QOL measures. To determine the internal consistency of baseline QUID Total, Stress and Urge Scores, Cronbach's $\alpha$ statistic and $95 \%$ lower confidence bounds were calculated (13).

We assessed construct validity by testing specific hypotheses regarding the QUID Stress and Urge scores in the Stress and Mixed UI groups, including 1) QUID Urge scores will be higher in the ATLAS Mixed UI group than in the ATLAS Stress UI group, and 2) QUID Stress scores will be greater than QUID Urge scores in the ATLAS Mixed UI group. Paired t-tests were used to compare these scores. In addition, we summarized the proportion of participants with QUID Stress scores $\geq 4$ in all ATLAS subjects, and with QUID Urge scores $\geq 6$ in the ATLAS Mixed UI group. We expected that these proportions would be high.

For the responsiveness to change analyses, the 3 intervention groups were pooled as treatment assignment remained blinded due to ongoing follow-up of study participants. Changes from baseline to 3 months in the QUID and other symptom and QOL measures were calculated (change score $=3$ month score - baseline score). Pre-defined hypotheses related to expected changes in the QUID scores after treatment included: 1) QUID Stress scores will significantly improve (scores decrease) from baseline to 3 months, 2) The change in QUID Stress scale scores will be greater than that seen in QUID Urge scale scores and 3) QUID Total and QUID Stress change scores will correlate with the PGI-I score. Changes were analyzed with paired t-tests, Wilcoxon sign-rank tests and the test described by Agresti (14) (for the ISI).

Responsiveness was also assessed by calculating the QUID effect size (ES) and standardized response mean (SRM). These measures evaluate change in relation to sample variation, providing a means of demonstrating that change has occurred and of presenting that change in a standardized metric (15). The ES was calculated as the change in mean score divided by the standard deviation (SD) of the baseline score, and the SRM as the change in mean score divided by the SD of the change (16).

\section{Results}

Four hundred and forty-four women were enrolled in the ATLAS trial, including 200 with SUI and 244 with mixed (stress-predominant) UI. Patient characteristics and symptom and QOL outcome measures at baseline are presented in Table I. Overall, the mean \pm SD age was $50 \pm 12$ years; $85 \%$ were white. Eight percent had prior UI or prolapse surgery. The SUI group was younger, more educated, more often pre-menopausal and had lower body mass index (BMI) compared to the mixed UI group. Women with mixed UI more often reported hypertension than those with SUI (75 (31\%) vs. 39 (20\%), p=0.009), but rates of other common medical problems did not differ between the groups. Diary measurements indicate a greater number of total leakage episodes, pads used, and voids in the mixed UI group. Compared to the SUI patients, the mixed UI group had greater QUID-Stress, Urge, and Total scores, greater severity of UI, and greater symptom distress and impact on daily living in all 3 PFDI and PFIQ scales.

The baseline individual QUID item responses and scores are summarized for the Stress UI (Table IIA) and Mixed UI (Table IIB) groups. Fewer than $1 \%$ of responses to each QUID item were missing. The range of item responses was good for all items and reflected the 
study inclusion/exclusion criteria and the group definitions (stress vs. mixed UI). QUID item-total correlations, a measurement of homogeneity within the stress and urge item sets, were moderate for the Stress scale and higher for the Urge scale.

QUID internal consistency at baseline was moderate to good with Cronbach's $\alpha$ (lower 95\% confidence bound) of 0.75 (0.72) for QUID Total scores, 0.64 (0.59) for QUID Stress scores, and 0.87 (0.85) for QUID Urge scores overall.

Table III displays baseline correlations between QUID Stress, Urge and Total scores with other UI symptom and QOL measures to determine QUID convergent and discriminant validity. QUID Stress scores correlated moderately with UDI-Stress scores $(\mathrm{r}=0.68)$ and diary SUI episodes $(\mathrm{r}=0.41)$, and, as expected, weakly with UDI-Irritative scores $(\mathrm{r}=0.28)$. QUID Urge scores correlated moderately with UDI-Irritative scores $(\mathrm{r}=0.68)$ and diary UUI episodes ( $\mathrm{r}=0.45)$, and weakly with UDI-Stress scores ( $\mathrm{r}=0.29)$. QUID Urge scores had a weak inverse correlation with SF-36 PCS and MCS scores (more urge UI symptoms associated with poorer mental and physical health-related QOL) ( $\mathrm{r}=-0.37$ and -0.30 , respectively), but otherwise, QUID scores had non-significant or very weak correlations with the sexual function and generic health measures (Table III).

As presented in Table I, the mean QUID Urge score at baseline in the mixed UI group was higher than in the SUI group (5.9 \pm 3.1 compared with $2.8 \pm 2.8, \mathrm{p}<0.0001)$. Similarly, QUID Stress scores were higher than QUID Urge scores in the mixed UI group $(8.9 \pm 3.2$ vs. $5.9 \pm 3.1, \mathrm{p}<0.0001)$. A substantial proportion $(403,93.3 \%)$ of women had QUID Stress scores $\geq 4$, including $176(90.7 \%)$ in the stress UI group and227 (95.4\%) in the mixed UI group. One-hundred thirty-four (56.3\%) of women in the mixed UI group had a QUID Urge score $\geq 6$. By comparison, 33 (16.9\%) of women in the stress UI group had an Urge score $\geq$ 6.

Three hundred sixteen subjects had complete data at 3 months and 344 women provided at least some 3-month data, used to assess responsiveness to change. Changes in QUID scores and other UI outcome measures are presented in Table IV. All 3-month UI outcomes significantly improved, including QUID Stress and Urge scores (decreased to $4.1 \pm 3.4$ and $2.2 \pm 2.7$, respectively; $p<0.0001$ each), although QUID Stress scores improved more than the QUID Urge scores (difference $-1.9 \pm 3.5, \mathrm{p}<0.0001$ ). QUID Total, Stress, and Urge change scores positively correlated with the PGI-I (more negative symptom change scores associated with lower PGI-I scores; both suggest improvement after treatment) ( $\mathrm{r}=0.49$, 0.47 , and 0.34 , respectively; $\mathrm{p}<0.0001$ for all). The QUID Stress score ES was 1.3 and SRM was 1.2, suggesting a large change after therapy compared to sample variation. QUID Urge and QUID Total change scores' ES were 0.7 and 1.2 with SRM of 0.8 and 1.2, respectively.

\section{Discussion}

We evaluated the utility and psychometric properties of the QUID when used as an outcome measure in an intervention trial of women with SUI and stress-predominant mixed UI undergoing non-surgical treatments for SUI. In this setting, the QUID demonstrated acceptable internal consistency, construct validity (including convergent/discriminant validity) and responsiveness to change after therapy. These data support the use of the QUID not only as a tool for screening and diagnosing UI type, but also as a valid and responsive measure of overall and type-specific UI symptom frequency.

Questionnaires for UI can be divided into severity measures, condition-specific health related QOL measures, and diagnostic or screening questionnaires $(17,18)$. The potential to use the QUID as both a diagnostic tool and outcome measure makes it relatively unique amongst available UI questionnaires, as most UI questionnaires are limited to one or the 
other. The QUID was developed and validated to provide an accurate diagnosis of UI type. The QUID correctly diagnosed UI type in $80 \%$ of 117 women presenting for Urogynecologic care and demonstrated a sensitivity and specificity for SUI (Stress score $\geq$ 4) of $85 \%$ and $71 \%$ and for UUI (Urge score $\geq 6$ ) of $79 \%$ and $79 \%$ (3). A recent systematic review evaluating the most accurate way to determine type of UI in an office setting identified the QUID as one of the few available questionnaires to aid in the diagnosis of SUI and UUI (18).

The International Consultation on Incontinence Questionnaire - Urinary Incontinence Short Form (ICIQ-UI) is another short questionnaire that provides a UI symptom severity score as well as diagnostic information through a single non-scored item in which subjects indicate when they leak (e.g. with coughing and sneezing or on the way to the bathroom) (19). In a study comparing the ICIQ-UI diagnostic item to urodynamic diagnoses, the ICIQ-UI's sensitivities ranged from $0.48-0.70$ and specificities ranged from $0.66-0.92$ for UI diagnoses (stress, urge and mixed UI) (20). Unlike the ICIQ-UI, the QUID assesses frequencies of stress-specific and urge-specific UI symptoms, therefore offering both clinicians and researchers an easy, reliable method to quantify relative and absolute change in frequency of stress and urge UI symptoms after therapy.

A strength of the QUID is that it is relatively short with only 6 items. As such, it may be less vulnerable to missing data than longer questionnaires - in this study, fewer than $1 \%$ of responses to QUID questions were missing. QUID internal consistency differed slightly in this analysis from that originally reported (3). When originally developed and validated, QUID Stress and Urge scores demonstrated good internal consistency with Cronbach's $\alpha$ values of .85 and .87 , respectively. Internal consistency was slightly lower for the Stress score in this population (0.64) for unclear reasons. Internal consistency generally should be greater than 0.70 (21). However, Cronbach's $\alpha$ depends on the number of items as well as the magnitude of correlations amongst items within a scale. More items result in higher values for Cronbach's $\alpha$ (higher internal consistency) (21). Thus for a 3-item scale like the QUID-Stress, the internal consistency seen in this study is adequate, particularly when balanced against the advantages of a shorter questionnaire.

As we hypothesized, the QUID scales correlated with appropriate measures of UI severity and symptom bother including the bladder diary and UDI (convergent validity), but less so with measures of sexual function and generic health measures (discriminant validity). It is interesting that the QUID correlated more strongly with the UDI (a measure of symptom bother) than with the diary (a measure of symptom frequency). This suggests that the "bother" rating in the UDI is explained in large part by symptom frequency. Our results may also indicate that the type of measure used ("subjective" self-administered questionnaire vs. "objective" prospectively-recorded diary) influences responses to some extent. Similar to our findings (moderate correlation between QUID scores and diary results), past research shows the UDI also correlated moderately with numbers of incontinence episodes reported by bladder diary (6).

Comparisons of the QUID Stress and Urge scores between subjects in the stress and mixed UI groups were also consistent with our a priori hypotheses, further supporting the construct validity of the QUID. We did not anticipate inverse correlations between the UUI frequency as measured on the QUID-Urge scale and the mental and physical summary scores of the SF-36. A similar relationship was not seen with the QUID-Stress scale. This finding is consistent with several studies that suggest health-related QOL is more adversely affected by UUI than SUI $(22,23)$. However, most measures of UI severity and bother either do not correlate or correlate only weakly with generic QOL measures like the SF-36 (24). Possibly, 
this difference is attributable to demographic and other differences between the Mixed and Stress UI groups (e.g. older age, greater BMI, more prescription medications).

Responsiveness to change, or the ability of an instrument to detect change after treatment, is an essential psychometric property for any scale intended to assess an intervention $(21,24)$. Significant improvements in each of the QUID scales were demonstrated after 3 months of non-surgical UI treatment. These improvements correlated significantly with the patient's assessment of improvement (PGI-I). In addition, the ES of the change was high for each QUID scale (0.7 to 1.3) corresponding with good to excellent responsiveness $(15,25)$. The QUID responsiveness is similar to that of the ISI $(\mathrm{ES}=1.0)$ and the UDI $(\mathrm{ES}=.85)$ and greater than that of the number of UI episodes on the bladder diary (ES=.33). Thus, the QUID has good to excellent responsiveness in women undergoing non-surgical management for SUI or Stress predominant Mixed Incontinence. As the treatment effect of surgery is typically larger than that of non-surgical management, the responsiveness of the QUID to surgical treatment is expected to be even larger than seen in this study.

The population of the ATLAS trial is larger and more diverse in geographic location and UI severity than the original study that described the QUID, expanding the generalizability of this instrument. Other strengths of this study include its prospective design, the use of multiple validated outcome measures for comparison, and the use of well described standardized treatments. A limitation is the absence of patients with only UUI symptoms or urge-predominant mixed UI. As such, these findings may only be applicable to those with SUI or stress-predominant mixed UI. However, the mixed UI group in this study did report significant urge symptoms (average 4 UUI episodes per week on diary) and the study findings support the validity and responsiveness for the Urge scale in this population. Moreover, QUID Urge scores showed convergent validity with other validated urge measures including the UDI- Irritative scale and the number of UUI episodes recorded on the bladder diary. It seems unlikely that the QUID urge score would perform less well in a population with only UUI than in a population of patients with mixed UI as seen in this study.

\section{Conclusions}

The QUID is a short, valid and responsive instrument that can serve as a diagnostic tool to determine UI type and also as a measure of stress and urge UI symptom frequency before and after treatment. This versatility should prove useful to both clinicians and researchers.

\section{Acknowledgments}

Funding

Supported by grants from the Eunice Kennedy Shriver National Institute of Child Health and Human Development (K23 HD047654, U01 HD41249, U10 HD41268, U10 HD41248, U10 HD41250, U10 HD41261, U10 HD41263, U10 HD41269, and U10 HD41267), the Office of Research on Women's Health, and the National Institute of Diabetes and Digestive and Kidney Disease. 


\section{APPENDIX}

\section{Appendix}

The Questionnaire for female Urinary Incontinence Diagnosis (QUID)

\begin{tabular}{|l|c|c|c|c|c|c|}
\hline & $\begin{array}{c}\text { None of } \\
\text { the } \\
\text { time }\end{array}$ & Rarely & Once in awhile & Often & $\begin{array}{c}\text { Most of } \\
\text { the } \\
\text { time }\end{array}$ & $\begin{array}{c}\text { All of } \\
\text { the } \\
\text { time }\end{array}$ \\
\hline $\begin{array}{l}\text { Do you leak urine (even small drops), wet } \\
\text { yourself, or wet your pads or } \\
\text { undergarments.. }\end{array}$ & & & & & & \\
\hline 1. when you cough or sneeze? & $\square$ & $\square$ & $\square$ & $\square$ & $\square$ & $\square$ \\
\hline $\begin{array}{l}\text { 2. when you bend down or lift something } \\
\text { up? }\end{array}$ & $\square$ & $\square$ & $\square$ & $\square$ & $\square$ & $\square$ \\
\hline 3. when you walk quickly, jog or exercise? & $\square$ & $\square$ & $\square$ & $\square$ & $\square$ & $\square$ \\
\hline $\begin{array}{l}\text { 4. while you are undressing in order to use } \\
\text { the toilet? }\end{array}$ & $\square$ & $\square$ & $\square$ & $\square$ & $\square$ & $\square$ \\
\hline $\begin{array}{l}\text { 5. Do you get such a strong and } \\
\text { uncomfortable need to urinate that you } \\
\text { leak urine (even small drops) or wet } \\
\text { yourself before reaching the toilet? }\end{array}$ & $\square$ & $\square$ & $\square$ & $\square$ & $\square$ & $\square$ \\
\hline $\begin{array}{l}\text { 6. Do you have to rush to the bathroom } \\
\text { because you get a sudden, strong need to } \\
\text { urinate? }\end{array}$ & $\square$ & $\square$ & $\square$ & $\square$ & $\square$ & $\square$ \\
\hline
\end{tabular}

Scoring:

Each item scores 0 (None of the time), 1 (Rarely), 2 (Once in awhile), 3 (Often), 4 (Most of the time) or 5 (All of the time). Responses to items 1, 2 and 3 are summed for the Stress score; and responses to items 4, 5, and 6 are summed for the Urge score.

\section{References}

1. Nygaard I, Barber MD, Burgio KL, Kenton K, Meikle S, Schaffer J, Spino C, Whitehead WE, Wu J, Brody DJ. Prevalence of symptomatic pelvic floor disorders in US women. JAMA. 2008; 300:1311-1316. [PubMed: 18799443]

2. Martin JL, Williams KS, Abrams KR, Turner DA, Sutton AJ, Chapple C, Assassa RP, Shaw C, Cheater F. Systematic review and evaluation of methods of assessing urinary incontinence. Health Technol Assess. 2006; 10:1-132. iii-iv. [PubMed: 16487456]

3. Bradley CS, Rovner ES, Morgan MA, Berlin M, Novi JM, Shea JA, Arya LA. A new questionnaire for urinary incontinence diagnosis in women: development and testing. Am J Obstet Gynecol. 2005; 192:66-73. [PubMed: 15672005]

4. Richter HE, Burgio KL, Goode PS, Borello-France D, Bradley CS, Brubaker L, Handa VL, Fine PM, Visco AG, Zyczynski HM, Wei JT, Weber AM. Non-surgical management of stress urinary incontinence: ambulatory treatments for leakage associated with stress (ATLAS) trial. Clin Trials. 2007; 4:92-101. [PubMed: 17327249]

5. Bump RC, Mattiasson A, Bo K, Brubaker LP, DeLancey JO, Klarskov P, Shull BL, Smith AR. The standardization of terminology of female pelvic organ prolapse and pelvic floor dysfunction. Am J Obstet Gynecol. 1996; 175:10-17. [PubMed: 8694033]

6. Barber MD, Kuchibhatla MN, Pieper CF, Bump RC. Psychometric evaluation of 2 comprehensive condition-specific quality of life instruments for women with pelvic floor disorders. Am J Obstet Gynecol. 2001; 185:1388-1395. [PubMed: 11744914]

7. Sandvik H, Seim A, Vanvik A, Hunskaar S. A severity index for epidemiological surveys of female urinary incontinence: comparison with 48-hour pad-weighing tests. Neurourol Urodyn. 2000; 19:137-145. [PubMed: 10679830] 
8. Rogers RG, Coates KW, Kammerer-Doak D, Khalsa S, Qualls C. A short form of the Pelvic Organ Prolapse/Urinary Incontinence Sexual Questionnaire (PISQ-12). Int Urogynecol J Pelvic Floor Dysfunct. 2003; 14:164-168. discussion 168. [PubMed: 12955337]

9. Dennerstein L, Lehert P, Dudley E. Short scale to measure female sexuality: adapted from McCoy Female Sexuality Questionnaire. J Sex Marital Ther. 2001; 27:339-351. [PubMed: 11441518]

10. Ware JE Jr. Sherbourne CD. The MOS 36-item short-form health survey (SF-36). I. Conceptual framework and item selection. Med Care. 1992; 30:473-483. [PubMed: 1593914]

11. Furlong WJ, Feeny DH, Torrance GW, Barr RD. The Health Utilities Index (HUI) system for assessing health-related quality of life in clinical studies. Ann Med. 2001; 33:375-384. [PubMed: 11491197]

12. Yalcin I, Bump RC. Validation of two global impression questionnaires for incontinence. Am $\mathbf{J}$ Obstet Gynecol. 2003; 189:98-101. [PubMed: 12861145]

13. Feldt LS. The approximate sampling distribution of Kuder-Richardson reliability coefficient twenty. Psychometrika. 1965; 30:357-370. [PubMed: 5216223]

14. Agresti, A. Categorical Data Analysis. John Wiley; New York: 1990.

15. Revicki D, Hays RD, Cella D, Sloan J. Recommended methods for determining responsiveness and minimally important differences for patient-reported outcomes. J Clin Epidemiol. 2008; 61:102-109. [PubMed: 18177782]

16. Wyrwich KW, Bullinger M, Aaronson N, Hays RD, Patrick DL, Symonds T. Estimating clinically significant differences in quality of life outcomes. Qual Life Res. 2005; 14:285-295. [PubMed: 15892420]

17. Barber MD. Questionnaires for women with pelvic floor disorders. Int Urogynecol J Pelvic Floor Dysfunct. 2007; 18:461-465. [PubMed: 17120170]

18. Holroyd-Leduc JM, Tannenbaum C, Thorpe KE, Straus SE. What type of urinary incontinence does this woman have? JAMA. 2008; 299:1446-1456. [PubMed: 18364487]

19. Avery K, Donovan JD, Peters TJ, Shaw C, Gotoh M, Abrams P. ICIQ: A brief and robust measure for evaluating the symptoms and impact of urinary incontinence. Neurourology and Urodynamics. 2004; 23:322-330. [PubMed: 15227649]

20. Espuna-Pons M, Dilla T, Castro D, Carbonell C, Casariego J, Puig-Clota M. Analysis of the value of the ICIQ-UI SF questionnaire and stress test in the differential diagnosis of the type of urinary incontinence. Neurourol Urodyn. 2007; 26:836-841. [PubMed: 17330896]

21. Streiner, DL.; Norman, GR. Health Measurement Scales: A practical guide to their development and use. Oxford University Press; New York: 1995.

22. Wyman JF, Harkins SW, Choi SC, Taylor JR, Fantl JA. Psychosocial impact of urinary incontinence in women. Obstet Gynecol. 1987; 70:378-381. [PubMed: 3627585]

23. Simeonova Z, Milsom I, Kullendorff AM, Molander U, Bengtsson C. The prevalence of urinary incontinence and its influence on the quality of life in women from an urban Swedish population. Acta Obstet Gynecol Scand. 1999; 78:546-551. [PubMed: 10376867]

24. Donavan, J.; Bosch, R.; Gotoh, M.; Jackson, S.; Naughton, M.; Radley, S.; Valiquette, L.; Batista, J.; Avery, K. In: Abrams, P.; Cardozo, L.; Khoury, S.; Wein, A., editors. Symptom and Quality of Life Assessment; 3rd International Consultation on Incontinence; Paris: Health Publication Ltd. 2005; p. 519-584.

25. Crosby RD, Kolotkin RL, Williams GR. Defining clinically meaningful change in health-related quality of life. J Clin Epidemiol. 2003; 56:395-407. [PubMed: 12812812] 
Table 1

Baseline characteristics and symptom and QOL measures in the overall, stress UI and mixed UI groups

\begin{tabular}{|c|c|c|c|c|}
\hline Characteristic/Measures & $\begin{array}{l}\text { Overall } \\
(n=444)\end{array}$ & $\begin{array}{l}\text { Stress UI group } \\
(\mathbf{n}=\mathbf{2 0 0})\end{array}$ & $\underset{(n=244)}{\operatorname{Mixed~UI~group~}}$ & p-value* \\
\hline Age (y) & $49.7 \pm 11.9$ & $47.2 \pm 11.3$ & $51.8 \pm 12.0$ & $<0.001$ \\
\hline Race & & & & 0.800 \\
\hline White/Caucasian & $378(85.1)$ & $169(84.5)$ & $209(85.7)$ & \\
\hline Black/African-American & $45(10.1)$ & $20(10.0)$ & $25(10.3)$ & \\
\hline Asian & $8(1.8)$ & $3(1.5)$ & $5(2.1)$ & \\
\hline Other & $13(2.9)$ & $8(4.0)$ & $5(2.1)$ & \\
\hline Ethnicity & & & & 0.148 \\
\hline Hispanic & $33(7.4)$ & $19(9.5)$ & $14(5.7)$ & \\
\hline Non-Hispanic & $411(92.6)$ & $181(90.5)$ & $230(94.3)$ & \\
\hline Education & & & & 0.043 \\
\hline Less than high school & $18(4.05)$ & $5(2.5)$ & $13(5.3)$ & \\
\hline High school & $83(18.7)$ & $32(16.0)$ & $51(20.9)$ & \\
\hline Some college & $146(32.9)$ & $65(32.5)$ & $81(33.2)$ & \\
\hline 4 years of college & $107(24.1)$ & $54(27.0)$ & $53(21.7)$ & \\
\hline Graduate/professional degree & $90(20.3)$ & $44(22.0)$ & $46(18.9)$ & \\
\hline Current smoker & $51(11.5)$ & $21(10.5)$ & $30(12.3)$ & 0.654 \\
\hline \multicolumn{5}{|l|}{ Parity- } \\
\hline \# cesarean deliveries & $0.3 \pm 0.7$ & $0.3 \pm 0.7$ & $0.3 \pm 0.7$ & 0.565 \\
\hline \# vaginal deliveries & $2.0 \pm 1.5$ & $1.9 \pm 1.2$ & $2.1 \pm 1.7$ & 0.425 \\
\hline Menopausal Status & & & & $<0.001$ \\
\hline Pre & $214(48.2)$ & $118(59.0)$ & $96(39.3)$ & \\
\hline Post & $187(42.1)$ & $60(30.0)$ & $127(52.1)$ & \\
\hline Not sure & $43(9.7)$ & $22(11.0)$ & $21(8.6)$ & \\
\hline Prior hysterectomy & $110(24.8)$ & $39(19.5)$ & $71(29.1)$ & 0.021 \\
\hline Prior prolapse/UI surgery & $37(8.4)$ & $14(7.0)$ & $23(9.4)$ & 0.393 \\
\hline \# prescription meds & $2.2 \pm 2.5$ & $1.6 \pm 2.2$ & $2.6 \pm 2.6$ & $<0.001$ \\
\hline BMI $\left(\mathrm{kg} / \mathrm{m}^{2}\right)$ & $29.4 \pm 6.9$ & $28.4 \pm 6.8$ & $30.3 \pm 7.0$ & 0.002 \\
\hline POP-Q Stage & & & & 0.476 \\
\hline 0 & $47(10.6)$ & $21(10.5)$ & $26(10.7)$ & \\
\hline I & $206(46.5)$ & $89(44.5)$ & 117 (48.2) & \\
\hline II & $190(42.9)$ & $90(45.0)$ & $100(41.2)$ & \\
\hline
\end{tabular}




\begin{tabular}{|c|c|c|c|c|}
\hline Characteristic/Measures & $\begin{array}{l}\text { Overall } \\
(n=444)\end{array}$ & $\begin{array}{c}\text { Stress UI group } \\
(\mathbf{n}=\mathbf{2 0 0})\end{array}$ & $\underset{(n=244)}{M}$ & p-value* \\
\hline UI episodes- stress & $15.7 \pm 18.6$ & $12.5 \pm 13.6$ & $18.4 \pm 21.5$ & $<0.001$ \\
\hline UI episodes- urge & $2.1 \pm 3.9$ & $0.0 \pm 0.0^{\dagger}$ & $3.8 \pm 4.6$ & $<0.001$ \\
\hline UI episodes- other & $0.9 \pm 2.9$ & $0.1 \pm 0.7$ & $1.5 \pm 3.7$ & $<0.001$ \\
\hline UI episodes- total & $18.7 \pm 22.0$ & $12.5 \pm 13.7$ & $23.8 \pm 25.9$ & $<0.001$ \\
\hline Pads - total & $9.1 \pm 10.9$ & $6.2 \pm 7.7$ & $11.4 \pm 12.4$ & $<0.001$ \\
\hline Voids- total & $62.5 \pm 18.8$ & $59.8 \pm 17.8$ & $64.7 \pm 19.3$ & 0.003 \\
\hline QUID- Total (0-30) & $12.9 \pm 5.3$ & $10.5 \pm 4.7$ & $14.8 \pm 5.0$ & $<0.001$ \\
\hline QUID-Stress (0-15) & $8.4 \pm 3.2$ & $7.7 \pm 3.2$ & $8.9 \pm 3.2$ & $<0.001$ \\
\hline QUID-Urge (0-15) & $4.5 \pm 3.3$ & $2.8 \pm 2.8$ & $5.9 \pm 3.1$ & $<0.001$ \\
\hline Incontinence Severity Index & & & & 0.001 \\
\hline Slight (1-2) & $18(4.2)$ & $11(5.7)$ & $7(3.0)$ & \\
\hline Moderate (3-6) & $134(31.3)$ & $71(36.6)$ & $63(26.9)$ & \\
\hline Severe (8-9) & $239(55.8)$ & $103(53.1)$ & $136(58.1)$ & \\
\hline Very severe (12) & $37(8.6)$ & $9(4.6)$ & $28(12.0)$ & \\
\hline UDI $(0-300)$ & $81.1 \pm 40.1$ & $67.5 \pm 32.8$ & $92.3 \pm 42.0$ & $<0.001$ \\
\hline UDI-Stress (0-100) & $47.3 \pm 20.0$ & $43.1 \pm 18.8$ & $50.7 \pm 20.3$ & $<0.001$ \\
\hline UDI-Irritative (0-100) & $19.6 \pm 15.8$ & $13.8 \pm 12.7$ & $24.4 \pm 16.6$ & $<0.001$ \\
\hline UDI-Obstructive (0-100) & $14.3 \pm 15.3$ & $10.6 \pm 12.4$ & $17.3 \pm 16.8$ & $<0.001$ \\
\hline UIQ (0-400) & $70.7 \pm 56.4$ & $57.6 \pm 47.7$ & $81.5 \pm 60.7$ & $<0.001$ \\
\hline PISQ-12 $(0-48)^{\S}$ & $34.2 \pm 5.86$ & $35.4 \pm 5.51$ & $33.1 \pm 5.98$ & 0.001 \\
\hline SPEQ (3-15) & $9.57 \pm 3.24$ & $9.89 \pm 3.19$ & $9.31 \pm 3.26$ & 0.074 \\
\hline \multicolumn{5}{|l|}{ SF-36 } \\
\hline Physical Component & $50.4 \pm 7.93$ & $52.1 \pm 6.69$ & $49.0 \pm 8.58$ & $<0.001$ \\
\hline Mental Component & $50.0 \pm 7.67$ & $50.9 \pm 6.65$ & $49.3 \pm 8.36$ & 0.149 \\
\hline HUI & $83.1 \pm 12.7$ & $85.0 \pm 10.8$ & $81.6 \pm 13.8$ & 0.012 \\
\hline
\end{tabular}

Data presented as mean $\pm \mathrm{SD}$ or $\mathrm{n}(\%)$.

$\mathrm{QOL}=$ quality of life, $\mathrm{UI}=$ urinary incontinence, $\mathrm{BMI}=$ body mass index, POP-Q=Pelvic Organ Prolapse Quantification, QUID=Questionnaire for Urinary Incontinence Diagnosis, UDI=Urinary Distress Inventory, UIQ=Urinary Impact Questionnaire, PISQ-12= Pelvic Organ Prolapse-Urinary Incontinence Sexual Function Questionnaire (short-form), SPEQ=Short Form Personal Experience Questionnaire, SF-36=Medical Outcomes Study 36-item Short-Form Health Survey, HUI=Health Utility Index.

* P-values for two-way comparison between Stress and Mixed UI groups

**

Diary variables all corrected to a 7-day total (variable total x 7 / \# valid days).

${ }^{\dagger}$ By definition, the Stress UI group had no Urge UI episodes recorded on the diary.

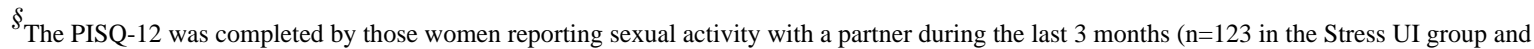
$\mathrm{n}=132$ in the Mixed UI group). 
Table II

Summary of QUID item responses and scores at baseline. Items 1, 2 and 3 make up the QUID Stress scale, and items 4, 5, and 6 the QUID Urge scale

\begin{tabular}{|c|c|c|c|}
\hline \multicolumn{4}{|l|}{ A. Stress UI Group (N=200) } \\
\hline QUID Items & $\begin{array}{c}\text { Responses } \\
(\mathbf{n}(\%))\end{array}$ & $\begin{array}{l}\text { Item or Scale Score } \\
\quad(\text { mean } \pm \text { SD })\end{array}$ & Item-Total Correlation ${ }^{*}$ \\
\hline Item 1- Cough/sneeze & & $3.5 \pm 1.1$ & 0.30 \\
\hline All of the time (5) & $37(19.0)$ & & \\
\hline Most of the time (4) & $64(32.8)$ & & \\
\hline Often (3) & $55(28.2)$ & & \\
\hline Once in awhile (2) & $36(18.5)$ & & \\
\hline Rarely (1) & $2(1.0)$ & & \\
\hline None of the time $(0)$ & $1(0.5)$ & & \\
\hline Item 2- Bend down/lift up & & $1.6 \pm 1.4$ & 0.54 \\
\hline All of the time (5) & $3(1.6)$ & & \\
\hline Most of the time (4) & $24(12.4)$ & & \\
\hline Often (3) & $18(9.3)$ & & \\
\hline Once in awhile (2) & $52(26.8)$ & & \\
\hline Rarely (1) & $42(21.7)$ & & \\
\hline None of the time $(0)$ & $55(28.4)$ & & \\
\hline Item 3- Walk/jog/exercise & & $2.7 \pm 1.7$ & 0.42 \\
\hline All of the time (5) & $37(19.0)$ & & \\
\hline Most of the time (4) & $37(19.0)$ & & \\
\hline Often (3) & $32(16.4)$ & & \\
\hline Once in awhile (2) & $33(16.9)$ & & \\
\hline Rarely (1) & $24(12.3)$ & & \\
\hline None of the time $(0)$ & $32(16.4)$ & & \\
\hline QUID Stress Score & -- & $7.7 \pm 3.2$ & -- \\
\hline Median $\left(25^{\text {th }}, 75^{\text {th }}\right.$ percentile $)$ & & $8(5,10)$ & \\
\hline Range & & $1-15$ & \\
\hline Item 4- Undressing for toilet & & $0.9 \pm 1.0$ & 0.68 \\
\hline All of the time (5) & $1(0.5)$ & & \\
\hline Most of the time (4) & $1(0.5)$ & & \\
\hline Often (3) & $13(6.7)$ & & \\
\hline Once in awhile (2) & $36(18.5)$ & & \\
\hline Rarely (1) & $53(27.2)$ & & \\
\hline None of the time $(0)$ & $91(46.7)$ & & \\
\hline Item 5- Strong need to urinate & & $0.9 \pm 1.1$ & 0.73 \\
\hline All of the time (5) & $3(1.5)$ & & \\
\hline
\end{tabular}




\begin{tabular}{|c|c|c|c|}
\hline \multicolumn{4}{|l|}{ A. Stress UI Group ( $\mathbf{N = 2 0 0 )}$} \\
\hline QUID Items & $\begin{array}{c}\text { Responses } \\
(\mathbf{n}(\%))\end{array}$ & $\begin{array}{c}\text { Item or Scale Score } \\
\quad(\text { mean } \pm \text { SD })\end{array}$ & Item-Total Correlation * \\
\hline Most of the time (4) & $3(1.5)$ & & \\
\hline Often (3) & $9(4.6)$ & & \\
\hline Once in awhile (2) & $35(18.0)$ & & \\
\hline Rarely (1) & $53(27.2)$ & & \\
\hline None of the time $(0)$ & $92(47.2)$ & & \\
\hline Item 6- Rush to bathroom & & $1.0 \pm 1.1$ & 0.58 \\
\hline All of the time (5) & $1(0.5)$ & & \\
\hline Most of the time (4) & $8(4.1)$ & & \\
\hline Often (3) & $12(6.2)$ & & \\
\hline Once in awhile (2) & $35(18.0)$ & & \\
\hline Rarely (1) & $54(27.7)$ & & \\
\hline None of the time $(0)$ & $85(43.6)$ & & \\
\hline QUID Urge Score & -- & $2.8 \pm 2.8$ & -- \\
\hline Median $\left(25^{\text {th }}, 75^{\text {th }}\right.$ percentile $)$ & $2(0,5)$ & & \\
\hline Range & & $0-13$ & \\
\hline QUID Total Score & -- & $10.5 \pm 4.7$ & -- \\
\hline Median $\left(25^{\text {th }}, 75^{\text {th }}\right.$ percentile $)$ & & $10(7,13)$ & \\
\hline Range & & $2-28$ & \\
\hline
\end{tabular}

\begin{tabular}{|c|c|c|c|}
\hline \multicolumn{4}{|c|}{ B. Mixed UI Group (N=244) } \\
\hline QUID Items & $\begin{array}{l}\text { Responses } \\
(\mathbf{n}(\%))\end{array}$ & $\begin{array}{c}\text { Item or Scale Score } \\
\quad(\text { mean } \pm \text { SD })\end{array}$ & Item-Total Correlation* \\
\hline Item 1- Cough/sneeze & & $3.7 \pm 1.2$ & 0.39 \\
\hline All of the time (5) & $69(29.0)$ & & \\
\hline Most of the time (4) & $73(30.7)$ & & \\
\hline Often (3) & $54(22.7)$ & & \\
\hline Once in awhile (2) & $35(14.7)$ & & \\
\hline Rarely (1) & $3(1.3)$ & & \\
\hline None of the time $(0)$ & $4(1.7)$ & & \\
\hline Item 2- Bend down/lift up & & $2.3 \pm 1.4$ & 0.55 \\
\hline All of the time (5) & $12(5.0)$ & & \\
\hline Most of the time (4) & $35(14.7)$ & & \\
\hline Often (3) & $60(25.2)$ & & \\
\hline Once in awhile (2) & $69(29.0)$ & & \\
\hline Rarely (1) & $32(13.5)$ & & \\
\hline None of the time (0) & $30(12.6)$ & & \\
\hline Item 3- Walk/jog/exercise & & $2.9 \pm 1.6$ & 0.51 \\
\hline
\end{tabular}




\begin{tabular}{|c|c|c|c|}
\hline \multicolumn{4}{|l|}{ B. Mixed UI Group ( $N=244)$} \\
\hline QUID Items & $\begin{array}{c}\text { Responses } \\
(\mathbf{n}(\%))\end{array}$ & $\begin{array}{c}\text { Item or Scale Score } \\
\quad(\text { mean } \pm \text { SD })\end{array}$ & Item-Total Correlation ${ }^{*}$ \\
\hline All of the time (5) & $46(19.3)$ & & \\
\hline Most of the time (4) & $51(21.4)$ & & \\
\hline Often (3) & $52(21.9)$ & & \\
\hline Once in awhile (2) & $41(17.2)$ & & \\
\hline Rarely (1) & $25(10.5)$ & & \\
\hline None of the time $(0)$ & $23(9.7)$ & & \\
\hline QUID Stress Score & -- & $8.9 \pm 3.2$ & -- \\
\hline Median $\left(25^{\text {th }}, 75^{\text {th }}\right.$ percentile $)$ & & $9(7,11)$ & \\
\hline Range & & $0-15$ & \\
\hline Item 4- Undressing for toilet & & $1.9 \pm 1.1$ & 0.68 \\
\hline All of the time (5) & $3(1.3)$ & & \\
\hline Most of the time (4) & $14(5.9)$ & & \\
\hline Often (3) & $54(22.7)$ & & \\
\hline Once in awhile (2) & $86(36.1)$ & & \\
\hline Rarely (1) & $53(22.3)$ & & \\
\hline None of the time (0) & $28(11.8)$ & & \\
\hline Item 5- Strong need to urinate & & $2.0 \pm 1.1$ & 0.78 \\
\hline All of the time (5) & $4(1.7)$ & & \\
\hline Most of the time (4) & $13(5.5)$ & & \\
\hline Often (3) & $55(23.1)$ & & \\
\hline Once in awhile (2) & $91(38.2)$ & & \\
\hline Rarely (1) & $51(21.4)$ & & \\
\hline None of the time (0) & $24(10.1)$ & & \\
\hline Item 6- Rush to bathroom & & $2.0 \pm 1.3$ & 0.65 \\
\hline All of the time (5) & $10(4.2)$ & & \\
\hline Most of the time (4) & $18(7.6)$ & & \\
\hline Often (3) & $54(22.7)$ & & \\
\hline Once in awhile (2) & $75(31.5)$ & & \\
\hline Rarely (1) & $50(21.0)$ & & \\
\hline None of the time $(0)$ & $31(13.0)$ & & \\
\hline QUID Urge Score & -- & $5.9 \pm 3.1$ & -- \\
\hline Median $\left(25^{\text {th }}, 75^{\text {th }}\right.$ percentile $)$ & & $6(4,8)$ & \\
\hline Range & & $0-15$ & \\
\hline QUID Total Score & -- & $14.8 \pm 5.0$ & -- \\
\hline Median $\left(25^{\text {th }}, 75^{\text {th }}\right.$ percentile $)$ & & $15(11,18)$ & \\
\hline Range & & $2-30$ & \\
\hline
\end{tabular}

UI=urinary incontinence, QUID=questionnaire for Urinary Incontinence Diagnosis, $\mathrm{SD}=$ standard deviation $\mathrm{UI}=$ urinary incontinence, $\mathrm{QUID}=$ questionnaire for Urinary Incontinence Diagnosis, $\mathrm{SD}=$ standard deviation 
* Pearson correlation between the individual item response and the corresponding total Stress or Urge score omitting that item; $\mathrm{p}<0.0001$ for all item-total correlations.

Pearson correlation between the individual item response and the corresponding total Stress or Urge score omitting that item; $\mathrm{p}<0.0001$ for all item-total correlations. 
Table III

Convergent/Discriminant Validity- correlations between baseline QUID Stress, Urge and Total scores and other UI symptom and QOL measures $(n=444)$

\begin{tabular}{|c|c|c|c|}
\hline & QUID - Stress Scale & QUID - Urge Scale & QUID - Total \\
\hline & $\mathbf{r}^{*}$ & $\mathbf{r}^{*}$ & $\mathbf{r}^{*}$ \\
\hline \multicolumn{4}{|l|}{ Diary ${ }^{* *}$} \\
\hline UI episodes- stress & 0.41 & 0.27 & 0.42 \\
\hline UI episodes- urge & 0.21 & 0.45 & 0.41 \\
\hline UI episodes- other & $0.18^{\dagger}$ & 0.22 & 0.25 \\
\hline UI episodes- total & 0.41 & 0.34 & 0.46 \\
\hline UDI- Stress & 0.68 & 0.29 & 0.59 \\
\hline UDI- Irritative & 0.28 & 0.68 & 0.60 \\
\hline UDI- Obstructive & $0.16^{\dagger}$ & 0.42 & 0.36 \\
\hline UIQ & 0.37 & 0.48 & 0.52 \\
\hline ISI & 0.37 & 0.28 & 0.41 \\
\hline PISQ-12 & $-0.12^{\prime \prime}$ & -0.26 & -0.23 \\
\hline SPEQ & $-0.05^{¥}$ & -0.22 & $-0.17 \S$ \\
\hline SF-36 PCS & $-0.10^{/ /}$ & -0.37 & -0.29 \\
\hline SF-36 MCS & $-0.01^{¥}$ & -0.30 & -0.20 \\
\hline HUI & $0.04^{¥}$ & -0.21 & $-0.11^{\prime l}$ \\
\hline
\end{tabular}

QUID=Questionnaire for Urinary Incontinence Diagnosis, QOL=quality of life, UI=urinary incontinence, UDI=Urinary Distress Inventory, UIQ=Urinary Impact Questionnaire, ISI=Incontinence Severity Index, PISQ-12 = Pelvic Organ Prolapse-Urinary Incontinence Sexual Function Questionnaire- Short Form, SPEQ=Short Form Personal Experience Questionnaire, HUI=Health Utility Index

* Pearson correlations (except Spearman correlation for the ISI). P-values all $<0.0001$, unless otherwise indicated.

**

Diary variables all corrected to a 7-day total(variable total x 7 / \# valid days).

${ }^{\dagger} 0.0001 \leq$ p-value $<0.001$

$\S_{0.001 \leq \text { p-value }}<0.01$

" $0.01 \leq$ p-value $\leq 0.05$

$¥$ p-value $>0.05$ 
Table IV

Changes in QUID scores and other UI symptom and QOL measures after non-surgical stress UI therapy

\begin{tabular}{|l|c|c|c|}
\hline & $\begin{array}{c}\text { Baseline } \\
\text { (n=444) }\end{array}$ & $\begin{array}{c}\text { 3-month } \\
(\mathbf{n = 3 4 4})\end{array}$ & $\begin{array}{c}\text { Change* } \\
(\mathbf{n = 3 4 4 )}\end{array}$ \\
\hline QUID- Total (0-30) & $12.9 \pm 5.3$ & $6.3 \pm 5.2$ & $-6.5 \pm 5.4$ \\
QUID-Stress (0-15) & $8.4 \pm 3.2$ & $4.1 \pm 3.4$ & $-4.2 \pm 3.6$ \\
QUID-Urge (0-15) & $4.5 \pm 3.3$ & $2.2 \pm 2.7$ & $-2.3 \pm 2.7$ \\
\hline Diary UI Episodes & $15.7 \pm 18.6$ & $4.4 \pm 11.4$ & $-9.8 \pm 17.3$ \\
Stress & $2.1 \pm 3.9$ & $0.8 \pm 2.7$ & $-1.3 \pm 3.8$ \\
Urge & $0.9 \pm 2.9$ & $0.4 \pm 1.9$ & $-0.5 \pm 3.3$ \\
Other & $18.7 \pm 22.0$ & $5.5 \pm 12.6$ & $-11.7 \pm 21.0$ \\
Total & \multicolumn{3}{|c}{} \\
\hline ISI (n (\%)) & $0(0.0 \%)$ & $3(0.9 \%)$ & N/A \\
Dry (0) & $18(4.2)$ & $146(44.2 \%)$ & \\
Slight (1-2) & $134(31.3 \%)$ & $107(32.4 \%)$ & \\
Moderate (3 -6) & $239(55.8 \%)$ & $66(20.0 \%)$ & \\
Severe (8-9) & $37(8.6 \%)$ & $8(2.4 \%)$ & \\
Very severe (12) & $81.1 \pm 40.1$ & $46.2 \pm 35.9$ & $-34.1 \pm 38.3$ \\
\hline UDI (0-300) & $47.3 \pm 20.0$ & $27.6 \pm 20.8$ & $-19.2 \pm 22.3$ \\
UDI-Stress (0-100) & $19.6 \pm 15.8$ & $10.5 \pm 12.0$ & $-8.7 \pm 13.9$ \\
UDI-Irritative (0-100) & $14.3 \pm 15.3$ & $8.2 \pm 11.5$ & $-5.9 \pm 11.8$ \\
UDI-Obstructive (0-100) & $70.7 \pm 56.4$ & $37.4 \pm 46.6$ & $-33.5 \pm 44.1$ \\
\hline UIQ (0-100) & \multicolumn{2}{|c}{} \\
\hline
\end{tabular}

Data presented as mean \pm SD, unless otherwise indicated.

QUID=Questionnaire for Urinary Incontinence Diagnosis, UI=urinary incontinence, QOL=quality of life, ISI=Incontinence Severity Index, UDI=Urinary Distress Inventory, UIQ=Urinary Impact Questionnaire

* Change scores $=3$-month scores - baseline scores; $\mathrm{p}$-values (for within-group score changes) all $<0.0001$, except $\mathrm{p}=0.008$ for Diary UI EpisodesOther 